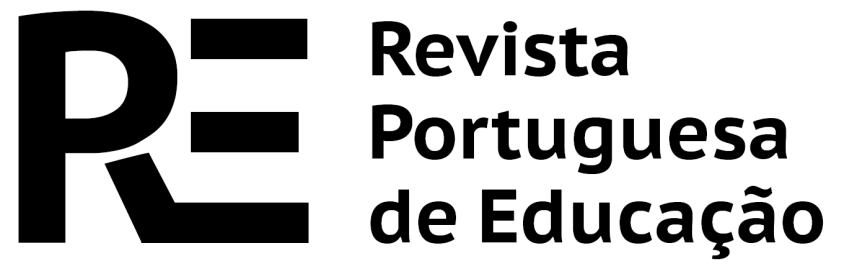

\title{
Que fatores contribuem para \\ o sucesso da gestão escolar? \\ A perspetiva dos diretores
}

\section{RESUMO}

Este estudo pretende fazer um balanço, na perspetiva dos diretores, da sua atuação à luz do presente modelo de administração escolar, na tentativa de apontar fatores de sucesso na gestão, bem como potenciais mudanças ao atual modelo, por eles propostas. Os dados foram recolhidos, em 2018, através de entrevistas exploratórias numa amostra estratificada, composta por 30 diretores em funções, no distrito do Porto, com uma experiência de gestão de, pelo menos, 4 anos. Os principais parâmetros que os diretores mais associam a uma melhor gestão são a formação especializada, as assessorias, a relação com a comunidade e o trabalho colegial. No que diz respeito às mudanças, as sugestões principais são o reforço da autonomia, a alteração da composição e das competências do Conselho Geral, a estabilidade legislativa e o apoio jurídico e contabilístico.

Palavras-chave: Gestão escolar; Diretor;

Fatores de sucesso; Mudanças

\section{INTRODUÇÃO}

A emergência do diretor, como órgão de administração unipessoal, operacionalizada pelo atual modelo de gestão, enquanto principal agente decisor dentro das escolas, decorre num contexto de accountability múltipla, uma vez consideradas as dependências que o diretor mantém no exercício da sua gestão (Afonso, 2018). Para além de depender internamente do Conselho Geral, depende dos serviços centrais do Ministério da Educação, do IGEC (Inspeção Geral da Educação e Ciência) e dos representantes das entidades da comunidade.

Os objetivos específicos deste trabalho são identificar, no âmbito do atual modelo de autonomia, administração e gestão escolar, as dificuldades, as contradições e as capacidades que os diretores associam, no desempenho das suas competências, à tomada de decisões, diferenciando os parâmetros que consideram ligados a resultados positivos da gestão. A partir desta

João Paulo Delgado ${ }^{i}$

Instituto Politécnico do Porto, Portugal

João M. S. Carvalhoii Universidade Portucalense, Portugal

Paula Romãoiii Instituto Politécnico do Porto, Portugal

Pedro Martins ${ }^{i v}$ Instituto Politécnico do Porto, Portugal 
reflexão, é enunciado um conjunto de mudanças que, na sua perspetiva, poderão contribuir para melhorar a gestão dos estabelecimentos públicos da educação pré-escolar e dos ensinos básico e secundário.

0 estudo adota uma abordagem metodológica qualitativa uma vez que procura compreender a realidade a partir das interpretações dos diretores, no e dos contextos em que atuam, valorizando-se os seus pontos de vista e as suas propostas de mudança. Os dados foram recolhidos, em 2018, através de entrevistas exploratórias numa amostra estratificada, composta por 30 diretores em funções, no distrito do Porto.

\section{O DIRETOR DE ESCOLA NO ATUAL MODELO DE GESTÃO}

0 atual regime jurídico de Autonomia, Administração e Gestão Escolar encontra-se consagrado no Decreto-Lei n. $-75 / 2008$, de 22 de abril, alterado pelo Decreto-Lei n.o 224/2009, de 11 de setembro, e, posteriormente, pelo Decreto-Lei n.o $137 / 2012$, de 2 de julho. 0 modelo assenta num conjunto de princípios em que se destaca a autonomia delegada por intermédio de um processo de negociação, a autoavaliação e avaliação externa, o reforço da participação das famílias e comunidades na direção estratégica das escolas e a eleição de um diretor em cada agrupamento, pondo termo a uma longa tradição em Portugal de liderança por órgãos colegiais.

Ao Conselho Geral, de acordo com o artigo 13ํㅡ, compete agora a eleição, por maioria absoluta, do diretor e participar na avaliação do seu desempenho [alíneas b) e q)], abandonando-se, deste modo, a opção por uma participação alargada na eleição do principal responsável pela gestão e administração da escola, interrompendo-se a tradição iniciada após a transição para a democracia (Carvalho, 2017). A organização interna da escola passou a estar centrada na pessoa do diretor e no reforço da cadeia hierárquica, na sequência da evolução que privilegiou a formação especializada do gestor e a verticalização da administração das escolas, assente no controlo dos resultados e na eficácia (Torres, 2008; Torres \& Palhares, 2009; Lima, 2011; Torres et al., 2018).

A inexistência de uma política articulada que concretize o reclamado reforço da autonomia e o articule com a inevitável restruturação do Ministério da Educação foi sendo artificialmente mitigada pela valorização das boas práticas. 0 conceito de boas práticas transporta, implicitamente, uma intenção uniformizadora e reprodutora, que corre o risco de se alhear da busca de respostas diferenciadas, adequadas às especificidades de cada contexto (Barroso, 2011a).

0 modelo de gestão, na sequência da legislação que o antecedeu, faz a apologia da autonomia da escola. De acordo com o n. -1 do Artigo 8. - do Decreto-Lei n. - 75/2008, a autonomia é a faculdade da escola "tomar decisões nos domínios da organização pedagógica, da organização curricular, da gestão dos recursos humanos, da ação social escolar e da gestão estratégica, patrimonial, administrativa e financeira", no âmbito das suas competências.

Embora a autonomia escolar possa ser encarada como um processo em curso (Barzanò, 2009) ou, segundo Formosinho et al. (2010), não ser um estado global em que a escola se instala definitivamente, tem sido historicamente vista com desconfiança por vários autores que a apodam de 
"Terra Prometida" (Lima \& Afonso, 1995) ou a encaram como "uma ficção necessária" (Barroso, 2004).

As referências à autonomia da escola portuguesa aparecem pela primeira vez na Lei de Bases do Sistema Educativo, a Lei no 46/86, de 14 de outubro, e desde aí figuram sempre nos normativos legais que enquadram a administração escolar.

Com o atual enquadramento legal, a autonomia, parafraseando Afonso (2010), passou a ser encarada como um instrumento de governação e de regulação, de acordo com as novas formas de atuação do Estado. E o rosto desta autonomia proclamada, e que constitui certamente uma das características mais marcantes e polémicas deste modelo de gestão escolar, é o diretor de escola. A emergência desta figura de gestão unipessoal, o principal agente decisor dentro das escolas, é encarada por alguns autores como um entrave à democratização da escola (Torres \& Palhares, 2009; Paro, 2010; Lima, 2011, 2014, 2018; Carvalho, 2013).

Apesar de ser a figura máxima da hierarquia escolar, o diretor tem a sua ação limitada por diversos fatores, dos quais se destacam uma tutela excessivamente reguladora e o aumento do controlo social da escola, agora representado institucionalmente pelo Conselho Geral, que já se vinha a verificar no modelo anterior (Silva, 2001; Barroso, 2004; Torres, 2007). Barroso (2010) fala em "autonomia contratualizada" e o mesmo autor, em 2011, fala mesmo em "autonomia imposta" e "esquizofrenia funcional", na ação dos diretores. A este propósito, diz Barroso (2011a, p. 21) que "os limiares de ação dos diretores são balizados pelo pragmatismo do que funciona e pela utopia do desejo, entre a imitação e a criação, entre a repetição e a reflexão, entre a transformação e a mudança, entre os constrangimentos e as oportunidades." Já Lima (2009, p. 247), refere-se ao aparecimento de um diretor "externamente fraco, especialmente perante a tutela", e que constitui, sob o ponto de vista da administração, o elo da tutela com as escolas.

Independentemente dos fatores condicionantes à sua atuação, e do deficit de autonomia, é indiscutível que o diretor é o rosto da escola e o principal responsável pela sua gestão (Torres \& Palhares, 2009; Afonso, 2018), pelo que a sua atuação tem sido objeto de numerosos estudos ao longo da última década. A título de exemplo, podemos citar vários autores que se debruçam sobre a problemática dos estilos de liderança e de gestão do diretor de escola, tais como: Torres e Neto-Mendes (2011), Carvalho (2013, 2017), Lima, M. (2014), Dutra (2017), ou Botler (2018). Parece-nos interessante referir também os estudos que abordam a relação entre o trabalho do diretor e a accountability (Afonso, 2010, 2012, 2015, 2018; Torres et al., 2018), bem como aqueles relacionados com a atuação dos diretores à luz da Nova Gestão Pública (Martins \& Macedo, 2017; Oliveira et al., 2017; Silva \& Sá, 2017).

No que concerne à eleição do diretor, o DL75/2008 estabelece duas condições que podem ser contraditórias e conflituantes entre si. Em primeiro lugar, o Conselho Geral aprecia, obrigatoriamente, o curriculum vitae de cada candidato, o projeto de intervenção na escola e tem em conta o resultado da entrevista individual realizada com cada candidato. No fim destes procedimentos, o Conselho Geral procede à eleição do diretor, considerandose eleito o candidato que obtenha maioria absoluta dos votos dos membros do Conselho Geral em efetividade de funções, o que pode significar que as etapas referidas anteriormente podem "valer zero" uma vez que a eleição do 
diretor é feita por voto secreto. No limite, pode ser eleito um diretor que tenha o pior currículo, o projeto de intervenção menos conexo e a entrevista mais débil, bastando para isso ter o apoio da autarquia, dos membros da comunidade local e um ou outro professor, aluno e/ou representante dos pais.

Em alternativa, a eleição do diretor poderia ser feita por nomeação ou por intermédio de um concurso público, competindo à tutela, às suas delegações regionais ou a um júri composto por uma equipa multidisciplinar, a seleção, atribuindo-se eventualmente ao Conselho Geral um papel consultivo. No caso de o diretor ser eleito na escola, o ato eleitoral poderia ser alargado à comunidade escolar (professores e representantes dos alunos, assistentes operacionais e técnicos, e encarregados de educação), de forma a imprimir ao ato maior democraticidade e participação, particularmente dos professores, o que coincide com as conclusões apresentadas por Silva e Machado (2013).

À luz destas evidências, parece-nos lícito afirmar que a figura do diretor é uma personagem central não apenas da vida escolar, mas também da produção científica relacionada com a administração e gestão escolar. Este estudo pretende, por um lado, recolher a opinião dos principais agentes decisórios nas escolas, os diretores, acerca das regras formais e das opções jurídico-institucionais do atual modelo de gestão; por outro lado, recolher a sua opinião sobre a sua prática, nos contextos em que atuam, na tentativa de apontar fatores de sucesso na gestão bem como potenciais mudanças ao atual modelo.

\section{METODOLOGIA}

A natureza exploratória deste estudo determinou a escolha de uma estratégia de abordagem metodológica qualitativa, com um desenho transversal e o método da entrevista estruturada. Esta metodologia de caráter indutivo apresenta uma posição epistemológica interpretativista, visto procurarmos a compreensão do fenómeno na base das opiniões dos diretores de escola ou agrupamento; uma posição ontológica construtivista, visto implicar o estudo das interações entre indivíduos e o fenómeno, conscientes de que este não é independente dos primeiros; e uma natureza interativa, no sentido em que beneficia da proximidade dos participantes com a realidade (Bryman, 2004). Assim, pretende-se valorizar a subjetividade, obter informação e descrever e interpretar múltiplas realidades, que são obviamente dependentes do contexto, sendo uma abordagem muito comum em estudos exploratórios (Creswall, 2003).

\subsection{PARTICIPANTES}

Os dados foram recolhidos através de entrevistas exploratórias numa amostra estratificada, com base em critérios de localização, tipo de agrupamento e anos de serviço, composta por 30 diretores em funções, em 2018, no distrito do Porto, Portugal, com uma experiência de gestão de, pelo menos, 4 anos. Foi garantido o total anonimato e confidencialidade aos entrevistados.

Como é desejável neste tipo de investigação, os investigadores pretenderam que a amostra escolhida para as entrevistas fosse o mais 
representativa possível de determinados contextos considerados importantes para este estudo exploratório. Assim, o facto de a escola ou agrupamento se localizar mais no litoral ou no interior do distrito, ter mais ou menos escolas, e o número de anos de serviço do diretor, foram consideradas variáveis cujas categorias deveriam ter representação, de modo a podermos obter uma possível e desejável maior variabilidade de visões sobre o fenómeno. Esta abordagem é chamada por alguns autores (por exemplo, Silverman, 2000) de amostragem intencional (purposive sampling). No entanto, como no caso deste estudo a escolha foi aleatória em cada grupo ou estrato de diretores, então verifica-se uma identificação com o método de amostragem estratificada.

0 sexo do entrevistado não fazia parte dos critérios de estratificação da amostra aleatória, mas verificou-se que 10 eram do sexo feminino e 20 do sexo masculino, sendo as suas médias de idade muito semelhantes $(\mathrm{H}-$ $54,28 ; \mathrm{DP}=6,22$ / $\mathrm{M}-54,67 ; \mathrm{DP}=5,05)$, assim como a média de anos de serviço $(H-8,8 ; \mathrm{DP}=2,02 / \mathrm{M}-8,4 ; \mathrm{DP}=2,59)$. A formação académica mais elevada destes diretores é a seguinte: Licenciatura (1); Programa de Formação em Gestão Pública - FORGEP (1); Pós-graduação em Gestão e Administração Escolar (18); Mestrado em Administração Escolar (8); e Doutoramento em Administração Escolar (2). 0 tamanho médio das escolas/agrupamentos é de 1606,27 alunos ( $\mathrm{DP}=753,45)$, com um valor mínimo de 80 e máximo de 3300 alunos.

\subsection{ENTREVISTA}

Os diretores foram contactados para marcação da entrevista. 0 testemunho dos diretores ajuda a compreender o significado profundo da experiência, a desvendar o sentido oculto que inevitavelmente comporta para os seus intervenientes. Disseminar a voz de quem é responsável pela gestão escolar é, aliás, a melhor forma de desvendar e explicar em primeira pessoa a experiência, a relação com o modelo legal que a configura, mas não determina, os resultados e os desafios que coloca. Por outro lado, possibilita passar da análise da decisão política, do discurso justificador que se expressa nas orientações institucionais e jurídicas, para o estudo da realização concreta dessas políticas, ao nível da realidade social.

0 guião de entrevista continha uma primeira parte com questões fechadas que permitiram caracterizar o diretor (por exemplo, anos de experiência) e a escola (por exemplo, número de alunos). Na segunda parte da entrevista foram colocadas duas questões abertas sobre dois tópicos: 1) fatores associados a resultados positivos na gestão de um agrupamento de escolas ou escola não agrupada; 2) mudanças no atual modelo de gestão que poderão contribuir para melhor gestão dos estabelecimentos públicos de ensino.

A aplicação da entrevista aos participantes foi antecedida pela explicação do objetivo do estudo e pela garantia do anonimato e da confidencialidade da sua identidade e do agrupamento que dirigem. Aos entrevistados foi assegurada a possibilidade de acederem, retificarem, desistirem ou retirarem as suas respostas deste estudo, sem nenhuma consequência negativa para si ou para o agrupamento.

As entrevistas tiveram uma duração média de 30 minutos. 


\subsection{ANÁLISE DE DADOS}

As gravações foram transcritas - constituindo o corpus de análise procurando respeitar integralmente o conteúdo transmitido, usando a pontuação para traduzir o ritmo e a emoção presente no discurso dos participantes. Procedeu-se à aplicação da técnica de análise de conteúdo, tendo os dados sido classificados em unidades de significado, temas e categorias. Dois investigadores leram e analisaram três entrevistas independentemente. A análise cruzada das duas primeiras entrevistas baseou o desenvolvimento da categorização dos dados, após discussão sobre os desacordos até a um consenso final. A unidade de significado foi estabelecida ao nível de cada frase. As unidades de significado foram classificadas em categorias - cada uma pertencendo exclusivamente a uma categoria - em consonância com o seu significado constitutivo. As categorias foram organizadas em temas, os quais resultaram dos tópicos introduzidos pelo guião da entrevista (Tabela 1).

Tabela 1

Exemplos de unidades de significado incluídas nas categorias identificadas

\begin{tabular}{|c|c|c|}
\hline & Categorias & Exemplos de unidades de significado \\
\hline \multirow{2}{*}{$\begin{array}{l}\text { Fatores de sucesso } \\
\text { na gestão de um } \\
\text { agrupamento de } \\
\text { escolas / escola não } \\
\text { agrupada }\end{array}$} & $\begin{array}{l}\text { Formação especi- } \\
\text { alizada }\end{array}$ & $\begin{array}{l}\text { “A formação dos professores e os professores terem } \\
\text { formação contínua, constante, (...)" (Entrevista n. }{ }^{\circ} 7 \text { ) } \\
\text { "A formação não tem sido aquela que nós precisamos, é } \\
\text { mais aquela que nos dão. (...) embora toda a formação é } \\
\text { positiva, mas poderia ser melhor, poderia ser um aspeto } \\
\text { mais positivo, se a formação fosse, de facto, ao encon- } \\
\left.\text { tro dos nossos problemas." (Entrevista } \text { n. }^{\circ} 16\right)\end{array}$ \\
\hline & $\begin{array}{l}\text { Assessoria de } \\
\text { qualidade }\end{array}$ & $\begin{array}{l}\text { "Era importante ter horas e poder ter assessorias, por } \\
\text { exemplo, assessorias jurídicas... conseguirmos ter... até, } \\
\text { se calhar, fora da escola, se não tivéssemos ninguém } \\
\text { dessa área... conseguir ter alguém numa assessoria } \\
\text { jurídica era importante... e financeira também." (Entre- } \\
\text { vista n. }{ }^{\circ} \text { 14) } \\
\text { "Uma situação destas, contabilisticamente, exige de nós } \\
\text { (...) mais formação e solicitar, dentro das possibilidades } \\
\text { (...) um apoio técnico externo. (......" (Entrevista } \text { n. }^{\circ} \text { 22) }\end{array}$ \\
\hline
\end{tabular}

Os dois investigadores analisaram a terceira entrevista, obtendo-se aproximadamente $90 \%$ de concordância na classificação das unidades de significado.

\section{RESULTADOS}

O discurso dos diretores de escolas estruturou-se em torno de dois temas principais, decorrentes do guião de entrevista: fatores de sucesso na gestão de um agrupamento de escolas/escola não agrupada e contributos para a evolução do modelo de gestão. A Figura 1 ilustra as categorias identificadas em cada tema. 
Figura 1

Temas e categorias identificadas no discurso dos participantes ( $n .^{\circ}$ de participantes e percentagem de participantes que se referiram a cada categoria)

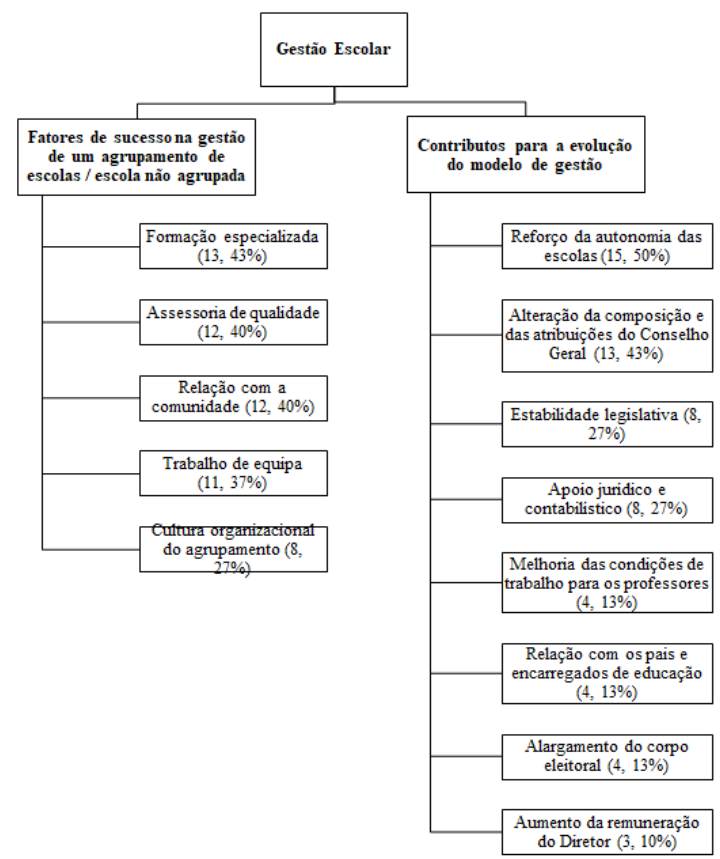

\subsection{FATORES DE SUCESSO NA GESTÃO DE UM AGRUPAMENTO DE ESCOLAS/ESCOLA NÃO AGRUPADA}

A análise das respostas dos diretores à questão sobre quais os fatores que mais contribuem para o sucesso na gestão das escolas permitiu identificar cinco categorias, de acordo com o número de afirmações congruentes com cada uma das categorias apuradas (Figura 1). Obviamente, todos estes fatores estão associados entre si, mas a sua identificação permite sublinhar aspetos particulares da gestão que os diretores, pela sua experiência, consideram ser os mais importantes fatores de sucesso das escolas.

FORMAÇÃO ESPECIALIZADA

A formação especializada do pessoal docente e não docente é o fator mais referenciado pelos diretores $(43 \%$ dos diretores). No que concerne à formação dos docentes, a referência abrange as instituições de ensino Superior com quem, pontualmente, são estabelecidos protocolos, para além da formação desenvolvida pelos Centros de Formação. Os diretores colocam o enfoque tanto na importância da formação docente no âmbito da especificidade da(s) disciplina(s) que lecionam como no âmbito das necessidades contempladas no Projeto Educativo das Escolas. Todavia, o processo de formação contínua de professores é alvo de críticas.

A formação dos professores e os professores terem formação contínua, constante, (...) ainda estamos muito no início, porque muitas das vezes chega aqui, em catadupa, formação para os professores que eles nem estão interessados, que, acho que muitas vezes é para cumprir calendário. (Entrevista n. ${ }^{-7}$ )

A formação não tem sido aquela que nós precisamos. É mais aquela que nos dão. (...). Embora toda a formação é positiva. Mas poderia 
ser melhor, poderia ser um aspeto mais positivo, se a formação fosse, de facto, ao encontro dos nossos problemas. (Entrevista n.ำ 16)

Quanto ao pessoal não docente, é destacada a pouca formação existente e a sua premência uma vez que, no caso dos assistentes operacionais, grande parte é contratada a termo certo e vêm de profissões fabris ou de outros empregos que não os qualificam para este tipo de funções, para além de nem todos terem o perfil de competências necessário para o seu exercício.

Relativamente à formação dos assistentes técnicos, os diretores são unânimes em considerar a urgência e a necessidade da sua formação em funções de âmbito administrativo, financeiro e/ou de recursos humanos. Foi referida, inclusive, a necessidade de ser disponibilizada aos próprios diretores das escolas formação especializada.

Ter formação especializada, eu acho que é fundamental. Além disso, também é essencial que os diretores, na minha opinião, que tivessem acesso a formação especializada contínua. (Entrevista n. ${ }^{27}$ )

Eu acho que era fundamental haver formação a nível financeiro... para o conselho administrativo. Acho que era importante haver uma formação especializada e prolongada. (Entrevista $n$. ${ }^{-14}$ )

\section{ASSESSORIA DE QUALIDADE}

Associada à necessidade de os diretores disporem de pessoal competente e habilitado, surge a questão da assessoria a que têm acesso, tendo sido referida por 12 diretores (40\%). Exemplo disso é a relevância dada ao trabalho feito pelos técnicos de contabilidade, nomeadamente em relação aos riscos financeiros das decisões dos diretores e à gestão financeira de orçamentos avultados.

Era importante ter horas e poder ter assessorias, por exemplo, assessorias jurídicas... conseguirmos ter... até, se calhar, fora da escola, se não tivéssemos ninguém dessa área... conseguir ter alguém numa assessoria jurídica era importante... e financeira também. (Entrevista n.ำ 14)

A possibilidade de se dispor de quadros técnicos especializados na área jurídica, na administração escolar, assim como nas áreas da psicologia ou do trabalho social ou de aceder ao seu apoio em serviços de proximidade é considerada essencial para as práticas da boa gestão e permitiria libertar os diretores de um conjunto de problemas que mais tempo e energias lhes consomem.

Uma situação destas, contabilisticamente, exige de nós (...) mais formação e solicitar, dentro das possibilidades (...) um apoio técnico externo. (...) 0 Ministério, eventualmente, através das várias DGEstE (...) se não... porque não estou a ver que seja possível colocar um técnico de direito e um técnico contabilístico em cada escola, mas termos, como consultoria, portanto, um gabinete de proximidade. (Entrevista n. $\stackrel{-}{22}$ ) 
RELAÇÃO COM A COMUNIDADE

A relação com a comunidade traduz-se nas inúmeras atividades que a escola organiza em parceria com a comunidade local, potenciando as oportunidades de cooperação. Doze diretores (40\%) referem a importância deste fator na gestão das escolas.

Ter a consciência de que a escola não pode estar fechada em si mesma, porque, se não, fica para trás. (...) Gosto de uma escola aberta, de ver cá dentro os pais a participarem, a contribuírem. (...) Isso é muito bom e têm sido parceiros (...) bastante ativos e presentes. Isso é muito positivo. Também a nossa relação com a autarquia é ótima (...) e com as Juntas de Freguesia que fazem parte da nossa área de ação. Temos, também, como aspeto positivo, o nosso plano de formação interno, em parceria, obviamente, com o Centro de Formação. (Entrevista n. ${ }^{-10}$ )

Os tempos atuais, de mudança acelerada, implicam a existência de redes de trabalho colaborativo de onde decorre a necessidade de encetar parcerias em vários dos domínios que a administração de uma escola abrange, nomeadamente com empresas que operam no âmbito de material escolar, informático, desportivo, alimentar, entre outros, assim como ao nível das infraestruturas desportivas, culturais, empresariais, centros de saúde, juntas de freguesia, associações desportivas, etc. Inclusive, a falta de recursos financeiros da escola pode, de certa forma, ser suprida com o estabelecimento de protocolos que permitam uma troca de bens e de serviços entre as escolas e outras entidades. 0 recurso à lei do mecenato é outra via possível e desejável a que recorrem também alguns diretores.

Outros stakeholders fundamentais são as associações de pais, com as quais se pode desenvolver um trabalho colaborativo muito importante, que promova a articulação do trabalho, no âmbito de um projeto educativo comum. Por exemplo, um diretor declara que

A escola tem de saber conviver com esses novos parceiros, quer sejam pais, quer sejam entidades reconhecidas aqui na zona e a própria autarquia também. (...) Outro dos aspetos que eu também acho importante é o envolvimento e o destaque que se dá, quer às forças vivas do meio, quer às próprias associações de pais, na sua representatividade. (Entrevista $n .{ }^{\circ} 4$ ).

TRABALHO DE EQUIPA

Em destaque está também o trabalho de equipa, mencionado por 11 diretores (37\%). Embora o Decreto-Lei n.o 75/2008 estabeleça que a direção é um órgão unipessoal, alterando uma tradição de mais de três décadas de direção de escolas com direções colegiais, os dados recolhidos neste estudo evidenciam a importância que os diretores conferem ao trabalho em equipa.

Aqui não funciono como diretor. Nós somos uma equipa. (Entrevista n. - 27)

A ênfase é colocada no trabalho colaborativo, na capacidade de o diretor saber ouvir e saber implicar os pares, para que sobressaia, com 
naturalidade, um sentido de corpo e de identidade na comunidade escolar, que tenha sempre presente que a realidade da ação das escolas é plural.

Quando digo "eu", tenho que abrir um parêntesis, porque somos "nós", é a minha equipa. Eu sem a minha equipa não existo, em absoluto. E, por isso, sendo um modelo unipessoal, portanto... a funcionalidade e a realidade da nossa ação é plural. (Entrevista n. ${ }^{\circ} 22$ )

Emerge das entrevistas feitas aos diretores a associação positiva que fazem entre os bons resultados alcançados pela escola com a capacidade que a mesma tem de ter uma identidade, uma singularidade pedagógica, de forma que, em cada escola, se encontrem formas de trabalho e dinâmicas de trabalhar em projeto, que levem os alunos a ter sucesso.

\section{CULTURA ORGANIZACIONAL DO AGRUPAMENTO}

A cultura organizacional do agrupamento é descrita por oito diretores (27\%) como a base para se constituir uma equipa coesa e solidária, unida por intermédio da utilização de símbolos comuns e por processos eficazes de comunicação interna.

O primeiro parâmetro que associo a resultados positivos é a capacidade que a escola tem de ter uma identidade, uma singularidade pedagógica... de que, em cada escola, se encontrem formas de trabalho, dinâmicas de trabalhar em projeto, que levem os alunos a ter sucesso. (Entrevista n.. 1)

Em síntese, as categorias dos fatores que os diretores mais associam a uma melhor gestão são a formação especializada, as assessorias, a relação com a comunidade, o trabalho colegial, a qualidade das parcerias estabelecidas e a existência de uma cultura organizacional singular e partilhada nas escolas e agrupamentos.

\subsection{CONTRIBUTOS PARA A EVOLUÇÃO DO MODELO DE GESTÃO}

Entre as mudanças que podem contribuir para o aperfeiçoamento do modelo, são referidos oito aspetos considerados como os fatores mais importantes.

\section{REFORÇO DA AUTONOMIA DAS ESCOLAS}

O reforço da autonomia das escolas é considerado por $50 \%$ dos diretores como um dos fatores que mais pode contribuir para a evolução do modelo, em diferentes áreas da gestão das escolas, possibilitando uma tomada de decisão mais célere, mais justa e adequada a cada contexto. Na gestão de recursos humanos, é referido o processo de substituição/colocação de professores e de alocação de horas, bem como o processo de renovação dos contratos com os técnicos especializados. O diretor é responsável pela prestação de contas, representando uma equipa que ele não escolheu e que pode eventualmente incluir pessoas nocivas à organização. Esta realidade seria atenuada com a atribuição da competência de contratação de uma parte do corpo docente, desde logo a parcela referente às necessidades residuais da escola. Os diretores deveriam igualmente ter poder para decidirem a recondução, de modo a promover-se a continuidade da equipa docente. 
Os diretores das escolas acho que têm dado provas de que sabem gerir e, portanto, acho que deviam ter um outro tipo de autonomia (...) não é só a autonomia financeira que nós reivindicamos (...) também autonomia pedagógica. (...). Podemos ter autonomia, também, em termos de gestão da carreira docente, não é? Acho que a contratação do pessoal docente e não docente teria muito melhores resultados se fosse feita diretamente pelas escolas. (Entrevista $n .^{-}$ 12)

$\mathrm{Na}$ área financeira, os diretores reclamam maior liberdade para a gestão do orçamento, assegurando-se, por exemplo, a possibilidade de mudança entre rubricas e a possibilidade de constituição de poupanças, de modo a ter reservas para fazer face às necessidades. Sugere-se a substituição do modelo atual de dotações orçamentais das escolas, subsidiário do orçamento do Instituto de Gestão Financeira, por um modelo de orçamento próprio semelhante ao que vigora no ensino superior. Isso permitiria, por exemplo, a organização de cursos de verão, ou atividades de tempos livres que fossem pagas, recorrendo aos seus trabalhadores ou contratando terceiros. É igualmente reclamada autonomia na exploração dos bufetes, eliminando as normas limitadoras que beneficiam o comércio concorrente local, e a cessação das limitações atuais de aplicação dos lucros das papelarias escolares.

$\mathrm{Na}$ área do currículo, reivindica-se maior flexibilidade na gestão curricular, que permitisse adequar tempos e disciplinas ao contexto específico de uma turma e às dificuldades nela identificadas, com o aval do conselho pedagógico.

São igualmente referidas outras áreas, tais como o reforço da autonomia na gestão das instalações, do pessoal não docente, do transporte escolar e até da fruta escolar, exemplos de decisões que poderão contribuir para a promoção do sucesso e que se encontram demasiado centralizadas.

Os diretores reconhecem também que, não obstante as competências pedagógicas associadas ao cargo, a tutela sobrecarrega o diretor com responsabilidades administrativas, nomeadamente através do preenchimento de plataformas, dificultando ou mesmo inviabilizando o desempenho das funções pedagógicas.

Isto é um modelo insustentável, há que dar o salto para um sítio diferente, em que a responsabilidade possa ser grande, mas a (...) autonomia para dirigir, para decidir, para gerir verdadeiramente recursos humanos e financeiros seja real. (Entrevista $n .{ }^{\circ}$ 1)

\section{ALTERAÇÃO DA COMPOSIÇÃO E DAS ATRIBUIÇÕES DO CONSELHO GERAL}

A alteração da composição e das atribuições do Conselho Geral foi amplamente comentada (43\% dos diretores). Quanto à composição, defende-se o reforço do peso dos professores e dos estudantes, em detrimento do peso das instituições, organizações e atividades representativas da comunidade local, que nem sempre serão selecionadas por lógicas de representação do contexto local, mas segundo critérios político partidários, associados à eleição ou manutenção no poder de um determinado diretor. Outras opiniões registam a ausência de participação da comunidade local na tomada de decisão, o facto de os seus membros não representarem efetivamente as instituições que os escolheram, de não possuírem as competências e o conhecimento necessário 
para discutirem uma parte significativa dos assuntos abordados, e de não responderem perante outro órgão da escola, fator que desresponsabiliza a sua intervenção.

Não se percebe muito bem quais são as suas competências e funções. Não se percebe muito bem, afinal, o que é que as pessoas lá estão a fazer. Porque não representam absolutamente ninguém, representam-se a si próprios. Um grupo extremamente pequeno, facilmente manipulável (...) Não tem responsabilidades, o Conselho Geral. (Entrevista n.. 20)

A participação da comunidade nem sempre acontece. Portanto, os elementos que estão no Conselho Geral são escolhidos da empresa ou da entidade ou do clube a, b, c ou d, e não têm a participação que deveriam de ter. (Entrevista n. ${ }^{\circ}$ )

Na perspetiva dos diretores, o Conselho Geral tem competências que não fazem sentido, como no caso da aprovação do orçamento, que é proposto pelo diretor, mas que o Conselho Geral pode obrigar a aumentar ou reduzir. Outras competências que o Conselho Geral não deveria desempenhar são a aprovação do projeto educativo, que é da iniciativa e da responsabilidade do diretor e a aprovação do Plano Anual de Atividades, que é avaliado pelo Conselho Pedagógico. Por outro lado, tem funções que não são efetivamente exercidas e um campo reduzido onde pode tomar iniciativas, defendendo-se a revisão das competências que lhe são atribuídas, ou mesmo a sua extinção.

Eu acho que era um órgão que não era necessário (...) e, portanto, se houvesse possibilidade, eu acho que devia ser extinto. (Entrevista $\mathrm{n}$. 12)

Os diretores sublinham a existência de uma contradição ou tensão entre o Conselho Geral, que prolonga a assembleia de escola do anterior modelo, que é contraproducente com um modelo de administração e gestão unipessoal. Algumas das opiniões recolhidas referem, inclusive, que o critério de escolha do diretor deverá passar a ser por nomeação ou por intermédio de um concurso público, competindo à tutela, às suas delegações regionais ou a um júri composto por uma equipa multidisciplinar a seleção, atribuindo-se ao Conselho Geral um papel consultivo.

ESTABILIDADE LEGISLATIVA

Um outro problema identificado pelos diretores é a ausência de estabilidade legislativa. A mudança contínua e rápida das regras, ao sabor da conjuntura política, dificulta a distribuição de serviço, bem como a preparação do ano letivo seguinte e inviabiliza a reflexão e a apropriação das práticas.

Não são aproveitadas as... as boas práticas. (...) Mudam os chefes do Ministério da Educação e tudo o que é bom vai para o lixo igualmente como tudo aquilo que é mau vai também para o lixo. (Entrevista $n$. o 16 )

As alterações sucessivas da legislação reduzem-se, por vezes, a alterações de pormenor que provocam insegurança e um desperdício de energias 
sobre qual a melhor forma de interpretar um detalhe numa norma, que pode ter uma importância reduzida. Um dos diretores sugere a adoção de regras rígidas que não permitam a publicação de documentos legislativos a partir de determinada época do ano, de modo a reduzir o impacto negativo das sucessivas alterações legais. Este estado das coisas produz nos docentes a convicção de que as regras não vigorarão muito tempo, o que mina a estabilidade dos alicerces em que deve assentar a escola pública e impede uma avaliação estruturadas das medidas e das reformas educativas.

APOIO JURÍDICO E CONTABILÍSTICO

$O$ apoio jurídico e contabilístico, sediado em cada escola ou centralizado no município, permitiria o acesso a um acompanhamento técnico que se revela indispensável para fazer face às competências e responsabilidades transferidas, de acordo com o discurso proferido pelos diretores. As assessorias poderiam proporcionar e fundamentar respostas concretas sobre questões do dia-a-dia, que salvaguardassem a decisão do diretor e a posição da escola, face aos riscos pessoais e institucionais que a tomada de decisão tantas vezes envolve, no âmbito civil e penal.

A parte principal e aquela que efetivamente me preocupa mais é a parte da contabilidade. E essa acho que passa, obrigatoriamente, por as escolas terem alguém que, efetivamente, domine essa área. (...) Acima de tudo, a segurança na área administrativa, que passaria por ter gente especializada, no mínimo a fazer a supervisão. (Entrevista n. -4 )

Eu acho que deveria haver da parte da tutela uma abertura para criar lugares para técnicos em áreas que são importantes. É o caso do Direito. Eu considero que hoje em dia o diretor lida com situações delicadíssimas, para as quais não tem conhecimento nem competência. (Entrevista $n . .97$ )

Este apoio especializado reduziria o trabalho burocrático e permitiria uma maior disponibilidade para gerir a componente pedagógica e potenciar os resultados das aprendizagens.

Ao nível contabilístico, é referido que a assessoria já existe nos cursos com financiamento da União Europeia, quando a escola dispõe de fundos para contratar uma empresa que é responsável pela contabilidade. Não se trata, pois, de inovar, mas tão só de dispor de recursos financeiros que permitam suportar a despesa resultante das assessorias.

MELHORIA DAS CONDIÇÕES DE TRABALHO PARA OS PROFESSORES

São ainda sugeridas mudanças no âmbito da melhoria das condições de trabalho dos professores, relativamente à estrutura da carga horária e ao impacto que a atual componente letiva e componente não letiva têm no trabalho dos docentes, pela dispersão e pelo desgaste que provocam. 0 congelamento da carreira docente, a ausência de compensações e a falta de valorização do papel do professor tem-se refletido no desempenho profissional de uma classe cada vez mais envelhecida. 
A revalorização do papel do professor, que tem que passar (...) no discurso político, nas entrevistas que os senhores ministros dão, etc.. (Entrevista $n . \stackrel{0}{10}$ )

Por outro lado, a falta de colocação de pessoal não docente nas escolas, tanto assistentes operacionais como assistentes técnicos, em número suficiente, é um problema que se agrava igualmente com o processo de envelhecimento, a passagem à reforma e a não reposição das vagas, e que se reflete nas condições de frequência escolar e no trabalho dos docentes.

\section{RELAÇÃO COM OS PAIS E ENCARREGADOS DE EDUCAÇÃO}

O reforço da relação com os pais e encarregados de educação é apontada como uma necessidade para o desenvolvimento de um trabalho de parceria que tenha como fulcro as aprendizagens de todos os estudantes, e não apenas do aluno que cada encarregado de educação representa.

Não é fácil ter muitos pais na escola. (...). Mas, a presença dos pais na escola é fundamental. Portanto, os filhos têm que sentir que a escola está ali, os professores estão ali, a direção está ali, estamos preocupados com eles, estamos a formá-los... e se tivermos o apoio dos pais e os pais acompanharem, nós notamos que esses alunos têm um percurso melhor. (Entrevista n. ${ }^{0}$ 12)

Uma mudança que poderá conduzir à presença dos pais e encarregados de educação no Conselho Pedagógico.

Neste modelo de gestão não me incomodaria absolutamente nada, até porque acredito nesta parceria, que, se em alguns órgãos escolares, nomeadamente, o conselho pedagógico, voltasse a ter os encarregados de educação. (Entrevista n. ${ }^{-22}$ )

ALARGAMENTO DO CORPO ELEITORAL

$O$ alargamento do corpo eleitoral na eleição do diretor surge como uma reivindicação de maior democraticidade e participação, em contraponto ao papel desempenhado neste processo pelo Conselho Geral. Quatro diretores (13\%) defendem uma eleição do diretor feita pela escola, através de um ato eleitoral alargado, em que os diversos atores pudessem participar, isto é, o conjunto de professores, de funcionários, os alunos e os pais, o que representaria uma inversão da tendência no modelo de gestão das escolas que se tem verificado nas últimas décadas e que se traduziu na redução do envolvimento dos atores da comunidade escolar nos processos de decisão (Barroso, 2011b; Silva \& Machado, 2013; Carvalho, 2017).

\section{AUMENTO DA REMUNERAÇÃO DO DIRETOR}

Por fim, o aumento da remuneração do diretor é referido por três diretores $(10 \%)$ como manifestamente insuficiente para a responsabilidade e exigência que o desempenho do cargo implica e em que o seu titular, estando no início ou meio da carreira, pode ter uma remuneração significativamente inferior à dos seus colaboradores.

Qual é órgão da administração pública em que um diretor ganha menos do que os seus funcionários? Eu ganho menos que um 
colega que está em topo de carreira. E tenho a responsabilidade que tenho. (Entrevista n. $\stackrel{0}{2}$ )

No que diz respeito às mudanças que poderão contribuir para a evolução do modelo, as sugestões principais são, em suma, o reforço da autonomia, a alteração da composição e das competências do Conselho Geral, a estabilidade legislativa e o apoio jurídico e contabilístico.

\section{CONSIDERAÇÕES FINAIS}

Os dados apurados permitem concluir que os diretores atribuem muita importância à formação do pessoal docente e não docente e evidenciam uma grande preocupação quanto à (in)existência de assessorias de qualidade, nomeadamente no que concerne à falta de assistentes técnicos com qualificação adequada para o exercício das suas funções. Este resultado parece sugerir que a tutela tem investido pouco na formação dos seus agentes educativos, sejam eles docentes ou não docentes. Na realidade, para aceder à categoria de assistente técnico, basta ter como habilitações o 12. o ano de escolaridade, não sendo exigida qualquer habilitação especializada para o exercício destas funções. Para além disso, existe a possibilidade de mobilidade entre os vários organismos da função pública, o que dá palco para esta indiferenciação de funções. É uma possibilidade conferida na lei, que provoca entropia no sistema, na medida em que muitos destes funcionários não acrescentam valor ao serviço que desempenham, não por falta de capacidade ou de profissionalismo, mas porque efetivamente não sabem como o fazer. E a tutela, não exigindo formação antes, também não lhes tem proporcionado formação contínua específica de qualidade.

Por outro lado, a importância atribuída ao trabalho colaborativo em equipa, assegurando um bom clima escolar, bem como o estreitar de relações com os stakeholders, dão nota de que as escolas têm privilegiado trabalho em rede, a fim de melhorarem os seus pontos fracos e potenciarem os fortes, contribuindo para o reforço da cultura do agrupamento.

Outras áreas, que se situam no nível macro, como as relativas à formação contínua, já referida anteriormente, ou à formalização de parcerias que implicam a mobilização de maiores recursos financeiros, já se encontram mais distantes da capacidade de decisão e são estas as que os diretores identificam como áreas-problema na gestão escolar. Nesta lógica, as parcerias entre a escola e a comunidade envolvente são, na nossa perspetiva, de sublinhar, porque espelham a responsabilidade social de cada ator e porque a escola é de todos e para todos. A comunidade escolar pode ser descrita como um puzzle em que cada peça é imprescindível e ocupa um lugar no projeto educativo da escola.

As narrativas dos diretores revelam uma luta constante para a escola determinar ela própria o seu modo de organização e as regras com que procura organizar o seu trabalho, não obstante a regulamentação e as coações exteriores, o que gera uma escola refém da burocracia (Lopes \& Ferreira, 2013). A atribuição de maior poder na tomada de decisão nas áreas da gestão financeira, curricular e noutros domínios do funcionamento organizacional teria como consequência, na opinião dos diretores entrevistados, uma maior responsabilização e uma efetiva prestação de contas, para lá da mera descrição dos procedimentos e do cumprimento dos 
normativos, permitindo dar provas das competências de gestão, viabilizandose deste modo uma efetiva avaliação dos resultados obtidos.

Por outro lado, há que também ter a clarividência de considerar que parte da tão reclamada autonomia está ao alcance das direções das escolas e, por vezes, não é exercida, por falta de visão estratégica e/ou de criatividade e/ou de inovação e/ou de know-how e/ou mesmo de um certo corporativismo. Por exemplo é possível, dentro dos normativos legais, construir as turmas com base em critérios que permitam adaptarem-se às caraterísticas dos alunos daquele contexto; fazer uma distribuição criteriosa de professores por turmas/alunos com caraterísticas diferentes; ser criterioso na atribuição do cargo de diretor de turma por perfis de turmas/alunos; fazer os horários das turmas tendo em consideração as idades dos alunos e os anos de exame; fazer o horário dos professores de forma equitativa, equilibrando o número de anos/turmas/cursos, dentro do grupo disciplinar; promover na escola um clima democrático de proporcionalidade na participação nos vários órgão de gestão intermédia da escola e outros projetos e grupos de trabalho; envolver os alunos e encarregados de educação na resolução de problemas de disciplina e afins. 0 exercício destas competências seria relevante para o sucesso educativo e escolar dos alunos e todas são permitidas no âmbito da implementação do Decreto-Lei noำ/2008.

Nas entrevistas realizadas, uma das palavras mais frequente foi autonomia, o que não deixa de nos fazer interrogar sobre quem deve recair a responsabilidade desta problemática sentida: será da falta de coragem dos diretores em assumir a autonomia decretada, mas não exercida? Será da tutela, que decreta, mas na prática põe inspetores no terreno a verificar a conformidade burocrática dos documentos? Será da "rotina" instalada dos professores que são resistentes à mudança? Será das escolas de formação de professores e dos cursos de administração escolar com programas curriculares desajustados da realidade? Será da crónica falta de recursos financeiros, que impede as escolas de investir na mudança? A sensação que fica é que existe uma orientação para que as escolas sejam autónomas, mas, por outro lado, a centralização é facilitadora para "quem manda", sendo muito forte a tentação de "uniformização", fazendo com que a autonomia seja encarada como uma "Terra Prometida" (Lima \& Afonso, 1995) ou como "uma ficção necessária” (Barroso, 2004).

Os diretores entrevistados relatam o facto de a tutela os sobrecarregar demasiado com responsabilidades administrativas, nomeadamente através do preenchimento de múltiplas plataformas e pela contínua prestação de contas, deixando pouco tempo para questões de índole pedagógica, o que só será possível com mais tempo disponível para a reflexão organizacional, igualmente potenciada pelas assessorias e pelo eventual alargamento das equipas. Neste contexto, os diretores relatam a falta de confiança da tutela, a qual se exprime na concessão formal de uma autonomia "entre aspas", plasmada em decreto, mas inexistente na prática, que se converte num instrumento de governação e de regulação (Afonso, 2010).

No nosso ponto de vista, é possível e desejável o modelo evoluir, nomeadamente ao nível da forma como o diretor é eleito, tal como já foi referido. No entanto, há que reconhecer que nem todos os problemas estão no modelo, mas, igualmente, na forma como o mesmo é interpretado, exercido e implementado pelos diretores e pelos restantes atores no processo educativo. Torna-se difícil compaginar alguns discursos de diretores que reclamam mais autonomia por parte da tutela quando, eles 
próprios, por vezes, exercem o seu mandato sem terem a preocupação de promover e incentivar a autonomia junto dos seus órgãos de gestão intermédia, incapazes de lhes conferir capacidade de decisão. Desta forma, evidenciam, eles próprios, falta de confiança nos seus pares, em contradição com o que reclamam da tutela.

No conjunto de mudanças propostas pelos diretores, a estabilidade das regras é identificada como um contributo para a evolução do modelo de gestão. As sucessivas alterações legislativas geram um significativo dispêndio de energia, desperdiçam as boas práticas, dificultam o planeamento estratégico, obrigam a uma necessidade de atualização constante, mobilizam recursos e impedem uma avaliação das reformas introduzidas no sistema.

A alteração da eleição, composição e funcionamento de certos órgãos de gestão, com destaque para o Conselho Geral, é igualmente reivindicada. Os diretores sublinham a existência de uma contradição ou tensão entre o Conselho Geral, que prolonga a assembleia de escola do anterior modelo, que é contraproducente com um modelo de administração e gestão unipessoal. Algumas das opiniões recolhidas referem, inclusive, que o critério de escolha do diretor deverá passar a ser por nomeação ou por intermédio de um concurso público, competindo à tutela, às suas delegações regionais ou a um júri composto por uma equipa multidisciplinar a seleção, atribuindo-se ao Conselho Geral um papel consultivo. Os entrevistados consideram ainda a possibilidade de o critério de escolha do diretor passar a ser por nomeação ou por concurso público. Em alternativa, no caso de o diretor ser eleito na escola, defendem que o ato eleitoral seja alargado à comunidade escolar, de forma a imprimir ao ato maior democraticidade e participação, particularmente dos professores (Torres \& Palhares, 2009; Paro, 2010; Lima, 2011, 2014, 2018; Silva e Machado, 2013). Ou seja, preferem uma solução que seja diferente da atualmente em vigor. O Conselho Geral é encarado, nestas perspetivas, como um mecanismo de pseudodemocraticidade, que serve como escudo para a não concretização e para o bloqueio das decisões do diretor, e que poderia eventualmente ser extinto.

Os tempos atuais são de mudanças rápidas e não deixa de ser curioso que a escola do século XXI, por via da publicação dos normativos mais recentes (Currículo para o Ensino Básico e Secundário, Perfil do Aluno à Saída da Escolaridade Obrigatória, Aprendizagens Essenciais, Autonomia e Flexibilidade Curricular, Educação Inclusiva e Estratégia Nacional de Educação para a Cidadania), releve a importância de capacitar os alunos para serem indivíduos autónomos, competentes e conscientes das suas responsabilidades, quando, em termos da gestão, administração e liderança escolares, se continue a promover uma quase total dependência da tutela, que decide à distância, globalmente, para o agir local.

Sendo a autonomia um modo de gerir as diversas dependências que enquadram e orientam o funcionamento das escolas, constata-se que a maioria das mudanças referidas pelos diretores remetem para a dimensão formal/legal ao nível do funcionamento do sistema educativo, nomeadamente a alteração e a estabilização das regras, a melhoria das condições de trabalho dos professores e do próprio diretor. Os diretores reclamam mais autonomia e relatam a falta de confiança da tutela, a qual se exprime na concessão formal de uma autonomia "entre aspas", plasmada em decreto, mas inexistente na prática. E esperam que o quadro orientador do funcionamento das escolas assegure as condições necessárias para o exercício efetivo dessa autonomia, possibilitando a liberdade na tomada de 
decisão, relativa a pessoas e recursos, no desenvolvimento das estratégias planificadas. É essa a expectativa dos diretores, e é esse o desafio que se coloca à conceção e implementação de um novo modelo de gestão escolar.

\section{REFERÊNCIAS}

Afonso, A. J. (2010). Gestão, autonomia e accountability na escola pública portuguesa: breve diacronia. Revista Brasileira de Política e Administração na Educação, 26(1), 13-30.

Afonso, A. J. (2012). Para uma concetualização alternativa de Accountability em Educação. Educação \& Sociedade, 33(119), 471-484.

https://doi.org/10.1590/S0101-73302012000200008

Afonso, A. J. (2015). Recuo ao cientificismo, paradoxos da transparência e corrupção em educação. Educação e Pesquisa, 41 (n. ${ }^{\circ}$ especial), 1313-1326.

https://doi.org/10.1590/S1517-9702201508145423

Afonso, A. J. (2018). O Diretor enquanto gestor e as diferentes pressões e dilemas da prestação de contas na escola pública. Roteiro (Edição Especial), 327344. https://doi.org/10.18593/r.v43iesp.17538

Barroso, J. (2004). A autonomia das escolas, uma ficção necessária. Revista Portuguesa de Educação, 17(2), 49-83.

Barroso, J. (2010). Conhecimento, actores e política. Sísifo. Revista de Ciências da Educação, 12, 37-50.

Barroso, J. (2011a). Direção de escolas e regulação das políticas: em busca do unicórnio. In A. Neto-Mendes, J. Costa \& A. Ventura (Orgs.), A emergência do Diretor da escola: questões políticas e organizacionais (pp. 11-22). Universidade de Aveiro.

Barroso, J. (2011b). Conhecimento e acção pública: as políticas sobre a gestão e autonomia das escolas em Portugal. In J. Barroso \& A. Natércio (Orgs.), Políticas educativas. Mobilização de conhecimentos e modos de regulação (pp. 27-58). Fundação Manuel Leão.

Barzanò, G (2009). Culturas de liderança e lógicas de responsabilidade. As experiências de Inglaterra, Itália e Portugal. Fundação Manuel Leão.

Botler, A. (2018). Gestão escolar para uma escola mais justa. Educar em Revista, 34(68), 89-105. https://doi.org/10.1590/0104-4060.57217

Bryman, A. (2004). Social Research Methods ( $2^{\mathrm{a}}$ ed). Oxford University

Press.

Carvalho, M. (2013). A Administração Escolar: Racionalidade ou Racionalidades?. Revista Lusófona de Educação, 25, 213-229.

Carvalho, M. (2017). O perfil do gestor da escola pública portuguesa. Revista Espaço do Currículo, 10(1), 82-9. https://doi.org/10.15687/rec.v10i1.32586.

Creswall, J. W. (2003). Research Design - Qualitative, Quantitative, and Mixed Methods Approaches ( $2^{a}$ ed). Sage Publications.

Dutra, C. (2017). A Contribuição da Gestão por Competências para uma Administração Escolar Participativa: um estudo de caso. Administração de Empresas em Revista, Curitiba, 17(18), 68-82.

Formosinho, J., Fernandes, A., Machado, J., \& Ferreira, H. (2010). Autonomia da Escola Pública em Portugal. Fundação Manuel Leão.

Lima, L., \& Afonso, A. J. (1995). The promised land: school autonomy, evaluation and curriculum decision making in Portugal. Educational Review, 47(2), 165-172. 
Lima, L. (2009). A democratização do governo das escolas públicas em Portugal. Sociologia. Revista da Faculdade de Letras da Universidade do Porto, 19, 227 253.

Lima, L. (2011). Diretor de escola: subordinação e poder. In A. NetoMendes, J. Costa \& A. Ventura (Orgs.), A emergência do Diretor da escola: questões políticas e organizacionais (pp. 47-66). Universidade de Aveiro.

Lima, L. (2014). A gestão democrática das escolas: do autogoverno à ascensão de uma pós-democracia gestionária?. Educação e Sociedade, 35(129), 10671083. https://doi.org/10.1590/ES0101-73302014142170

Lima, L. (2018). Por que é tão difícil democratizar a gestão da escola pública? Educar em Revista, 34(68), 15-28. https://doi.org/10.1590/0104-4060.57479

Lima, M. (2014). Estilos de gestão e a influência na administração escolar. Revista Internacional de Investigação em Ciências Sociais, 10(2), 230-238.

Lopes, A., \& Ferreira, E. (2013). A figura do Diretor - (des)continuidades narrativas de líderes e liderados em contexto escolar. Revista Portuguesa de Investigação Educacional, 13, 137-154.

Martins, F., \& Macedo, A. (2017). O Novo Modelo de Gestão e a Democratização e Participação na Escola: perspetivas de atores educativos. Revista de Estudios y Investigación en Psicología y Educación, vol. extr.(6), 85-89. https://doi.org/10.17979/reipe.2017.0.06.2288.

Oliveira, D. \& Duarte, A., \& Clementino, A. (2017). Nova Gestão Pública no contexto escolar e os dilemas dos(as) Diretores(as). Revista Brasileira de Política e Administração na Educação, 33(3), 707-726.

https://doi.org/10.21573/vol33n32017.79303

Paro, V. (2010). A educação, a política e a administração: reflexões sobre a prática do Diretor de escola. Educação e Pesquisa, 36(3), 763-778.

https://doi.org/10.1590/S1517-97022010000300008

Silva, G., \& Sá, V. (2017). O Diretor Escolar Em Portugal: formação e perfil profissional. Revista Espaço do Currículo, 10(1), 62-81.

https://doi.org/10.15687/rec.v10i1.33555

Silva, J. (2001). Cultura Escolar, Autoridade, Hierarquia e Participação: alguns elementos para reflexão. Cadernos de Pesquisa, 112, 125-135.

https://doi.org/10.1590/S0100-15742001000100006

Silva, M. \& Machado, J. (2013). A escolha do Diretor. Revista Portuguesa de Investigação Educacional, 13, 107-135.

Silverman, D. (2000). Doing Qualitative Research - A practical handbook. Sage Publications.

Torres, L. (2007). Cultura organizacional escolar: apogeu investigativo no quadro de emergência das políticas neoliberais. Educação e Sociedade, 28(98), 151179. https://doi.org/10.1590/S0101-73302007000100009

Torres, L. (2008). A escola como entreposto cultural: o cultural e o simbólico no desenvolvimento democrático da escola. Revista Portuguesa de Educação, 21(1), 59-81. https://doi.org/10.21814/rpe.13919

Torres, L., \& Palhares, J. (2009). Estilos de liderança e escola democrática. Revista Lusófona de Educação, 14, 77-99.

Torres, L., \& Neto-Mendes, A. (2011). Apresentação de "Administração Escolar: Estudos" de Lima, Licínio. Revista Portuguesa de Educação, 24(1), 249-257. https://doi.org/10.21814/rpe.3047

Torres, L., Palhares, J., \& Afonso, A. J. (2018). Marketing Accountability e Excelência na Escola Pública Portuguesa: A Construção da Imagem Social da Escola 
Através da Performatividade Académica. Arquivos Analíticos de Políticas Educativas, Arizona, 26(134), 1-28. https://doi.org/10.14507/epaa.26.3716

Informação dos autores:

i InED - Centro de Investigação e Inovação em Educação, Instituto Politécnico do Porto, Porto, Portugal. https://orcid.org/0000-0001-6977-8214

ii Universidade Portucalense, Porto, Portugal. http: //orcid.org/0000-0003-0683-296X

iii InED - Centro de Investigação e Inovação em Educação, Instituto Politécnico do Porto, Porto, Portugal. http: //orcid.org/0000-0002-3919-7563

iv InED - Centro de Investigação e Inovação em Educação, Instituto Politécnico do Porto, Porto, Portugal.

Toda a correspondência relativa a este artigo deve ser enviada para:

Paulo Delgado Escola Superior de Educação do Instituto Politécnico do Porto, Rua Dr. Roberto Frias 602, 4200-465 Porto, Portugal. pdelgado@ese.ipp.pt

Recebido em 20 de novembro de 2019

Aceite para publicação em 2 de janeiro de 2021 
Which factors contribute to the success of school management? The principals' perspective

\begin{abstract}
This study intends to take stock, from the perspective of the school principals, of their performance in the light of the present model of school administration, in an attempt to point out success factors in management, as well as potential changes to the current model, proposed by them. Data were collected in 2018 through exploratory interviews in a stratified sample, composed of 30 principals in office, in the district of Porto, with a management experience of at least 4 years. The main parameters that the principals associate more with better management are specialized training, advisory services, relationship with the community and collegiate work. With regard to changes, the main suggestions are the strengthening of autonomy, changes in the composition and powers of the General Council, legislative stability and legal and accounting support.
\end{abstract}

Keywords: School management; Principal;

Success factors; Changes 


\section{¿Qué factores contribuyen al éxito de la gestión escolar? La perspectiva de los directores}

\section{RESUMEN}

Este estudio pretende hacer un balance, desde la perspectiva de los directores, de su desempeño a la luz del modelo actual de administración escolar, en un intento de señalar factores de éxito en la gestión, así como posibles cambios al modelo actual, propuestos por ellos. Los datos fueron recolectados en 2018 a través de entrevistas exploratorias en una muestra estratificada, compuesta por 30 directores en funciones, en el distrito de Oporto, con una experiencia gerencial de al menos 4 años. Los principales parámetros que los directores asocian más con una mejor gestión son la formación especializada, la asesoría, la relación con la comunidad y el trabajo colegiado. En cuanto a los cambios, las principales sugerencias son el fortalecimiento de la autonomía, cambios en la composición y competencias del Consejo General, estabilidad legislativa y apoyo legal y contable.

Palabras-clave: Gestión escolar; Director;

Factores de éxito; Cambios 